\title{
On Social Action in Counseling and Psychology: Visions for the Journal
}

\author{
Tod Sloan, Lewis and Clark College \& Rebecca L. Toporek, San Francisco \\ State University
}

Let's pause for a moment to reflect on the roles a journal can fulfill in relation to the ultimate objectives of our work in the psychological and mental health professions. What exactly are we trying to accomplish? Most counselors, psychologists, and other mental health professionals would say that our work aims to contribute to the betterment of society. Our psychosocial work - whether it involves helping individuals or groups with problems in living, conducting research and teaching about human behavior, improving organizational functioning, or reducing conflict - is assumed to have at least an indirect positive impact on human well-being in society. We assume that the direct effects of what we do eventually spread in their impact. We think that better adjusted individuals should create fewer problems for others. We assume that greater insight into human behavior should find expression in more effective psychological interventions. Improved organizations should be more successful and all their members and clients should therefore be more fulfilled and satisfied. Similarly, the reduction of conflict should lead to greater peace and mutual understanding.

In turn, journals can serve as repositories for accumulated wisdom on questions of what we can do to make a difference and for lively debate on what should count as wisdom. The Journal for Social Action in Counseling and Psychology (JSACP) emerges at this moment in history as a space for examining challenges to the idea that the psychosocial effects of counseling and psychology are generally sufficient, positive, and benign. This challenge comes from at least two directions. First, we do not believe that sustaining and expanding the business of counseling and psychology as currently constituted will play a tangible role in the achievement of social justice or the construction of peace and social justice either locally or globally. Second, we are concerned that some practices associated with counseling and psychology are worse than ineffective and are, in fact, either part of the problem or do direct harm. Both of these claims are very serious. The associated questions are profound. Are psychosocial services actually contributing to the construction of a just society in significant ways? Or are they mostly a distraction that makes helpers feel good as they soothe people who have been more severely wounded by social forces? Are psychological and counseling practices so imbued with cultural biases that they essentially become tools of cultural colonization? Or are they universally applicable techniques that can be empirically validated once and for all?

Two energetic organizations, Counselors for Social Justice (CSJ), a division of the American Counseling Association, and Psychologists for Social Responsibility (PsySR), initiated JSACP as a 
forum for research and discourse regarding our contributions to social justice, peacebuilding, and social transformation. We will strive to foster a journal that is relevant to counselors, psychologists and related professionals as well as students and educators. Policy makers, activists, and community organizers should also find the content to be informative and relevant to their work. As the founding editors of JSACP, our vision for the journal reflects the missions of the sponsoring organizations as well as the notion that significant change is necessary within the fields of counseling, psychology and in the greater society. In this introduction we will present the vision for the journal and briefly discuss editorial policy and guidelines. This is our call to readers and potential authors.

We take this opportunity to describe the foundations of this journal including the missions of CSJ and PsySR as well as the intent of this journal and our vision as founding editors. We conclude this introduction by presenting the structure, format, and editorial policy to serve as guidelines for authors and readers.

\section{The Inception of JSACP: Counselors for Social Justice and Psychologists for Social Responsibility}

In 2005, the leaders of Counselors for Social Justice (CSJ) and Psychologists for Social Responsibility (PsySR) decided that one way to implement their mutual goals was to co-sponsor a journal that would highlight scholarship and community work that reflected their organizational ideals. Therefore, the missions and foci of these organizations are important to understand as foundations for this journal.

Counselors for Social Justice is a community of counselors, counselor educators, graduate students, and school and community leaders who seek equity and an end to oppression and injustice affecting clients, students, counselors, families, communities, schools, workplaces, governments, and other social and institutional systems. As outlined in their mission statement, (retrieved on May 23, 2007 from http://counselorsforsocialjustice.com/mission.html) CSJ is committed to:

- Challenging oppressive systems of power and privilege.

Implementing social action strategies including the Social Justice Advocacy Competencies (Lewis, Arnold, House, \& Toporek, 2002) through collaborative alliances with other ACA entities, counselor education programs, and $\mathrm{N}-16$ schools and community organizations.

- Disseminating social justice scholarship about sociopolitical and economic inequities facing counselors and clients/students in schools and communities.

Maintaining an active support network online and in person for engaging in social justice activities in schools and communities.

- Providing lively professional development to enhance counselor, counselor educator, and graduate student competency in social justice advocacy via ACA annual conference programs (Day of Action/Day of Learning), branches, regions, counselor education programs, $\mathrm{N}-16$ schools, and community agencies. 
Maintaining social justice advocacy resources online.

The mission of Psychologists for Social Responsibility (retrieved on May 23, 2007 fromhttp://www.psysr.org/about\%20us.htm) is to use "psychological knowledge and skills to promote peace with social justice at the community, national and international levels." The organization strives to: "apply the growing body of knowledge about conflict resolution and violence prevention; facilitate positive changes for victims and survivors of personal, community, and civil violence; advocate for basic human needs - including actions that decrease poverty, ensure ethnic and gender equality, increase work opportunity, promote healthy and sustainable environments, and achieve a wiser balance between human needs and military budgets; and, ensure that relevant information from psychology is used in local, national, and international public policy"

CSJ and PsySR have in common an interest in sustaining the efforts of those who muster the energies required to resist the dominant currents, to challenge oppression, and to work in solidarity with marginalized and exploited groups. The journal must serve as a resource for agents of change and also as an inspiration and a haven.

\section{Vision and Direction for the Journal for Social Action in Counseling and Psychology}

Central to the mission of JSACP is to promote discourse that is relevant to diverse cultural groups and communities. Four central intentions shape the journal.

- To bring social action research, practice, and training into the forefront of scholarly discourse

- To provide a forum for demonstrating effective interventions for addressing social issues

- To foster international and intercultural collaboration and understanding

- To encourage dialogue between individuals and communities toward the resolution of social problems

JSACP seeks to explore scholarship and research in ways that extend beyond traditional counseling and psychotherapy to present high quality, peer-reviewed work that represents state-of-the-art social action. Social action scholarship is transformational at a structural level, integrating ethical and community based methods and challenging systems of injustice and oppression. Social action requires that we go beyond individual and group clinical interventions for the ills of society. It requires that we directly examine and expose the roles of institutional arrangements, policies and powerful groups in preserving these ills and that we then act in a way that holds systems accountable and leads to their transformation.

\section{Format, Structure and Editorial Policy}

We hope to go beyond traditional literature in counseling and psychology to integrate voices of those not often heard in scholarly discourse and bring to light research and thought that is focused on social transformation. One of the central goals of JSACP is to make the discourse 
around social issues inclusive of many different voices. As a result, JSACP is designed to include a number of structural elements that will increase the number of voices, who we hear from, and what types of contributions are made to the discussion.

\section{Credibility and Scholarship}

We expect to challenge traditional discourse, while at the same time we believe it is important for the journal to take its place among the top scholarly journals of the field in order to potently serve as a catalyst and change agent. We hope the journal will become an exemplar of what is known as 'the scholarship of engagement' (see scholarshipofengagement.org), a movement aiming to open spaces for academics to ground their work more directly in response to communities in transformation. The journal must therefore maintain high scholarly standards as well as provide a forum for transformative research and writing. It is essential that the review process be one that strengthens scholarly discourse and nurtures alternative scholarly contributions. Upholding principles of a juried process and anonymous peer review, manuscripts submitted for the Scholarly Forum will be reviewed and evaluated in terms of consideration of models of social change and power; commitment to community and systems; clarity and readability for a wide audience; clearly articulated methods and implications for counseling and psychology; as well as reflexivity and attention to cultural issues.

\section{Community and Student Voices}

Within the counseling and psychology literature, the voices heard least often are those from the communities we serve and the students who will become the professionals. The majority of literature is written by academics and sometimes practitioners for educators and professionals. Our professions' expectations for literature to adhere to specific discipline specific writing rules and academic content often prohibit contributions from outside academia. We endeavor to bring the voices of community and students to the forefront using a review process that reflects the flexibility needed to include alternative voices yet upholds editorial standards for clarity of expression as well as contribution to the goals and principles of the journal and social change.

\section{Bilingual}

Many revolutionary ideas and transformations have come from international venues and activists. As one example, Paolo Freire's (1993) work in Brazil and elsewhere has made monumental impact on social justice, education and the psychology of social change. Similarly, Ignacio Martín-Baró (1994), working in El Salvador inspired an entire generation of psychologists in Central America to develop the foundations for a psychology of liberation. Much significant work has been done in Latin America as well as other parts of the world, yet this scholarship does not always make its way to the traditional counseling and psychological literature due to language and editorial differences. We envision that JSACP will serve as a conduit for significant scholarly and community work that is best expressed in Spanish to extend the possibilities beyond the borders of the English language to encompass the contributions toward social justice from Latin America and Mexico. Therefore, JSACP will publish both English and Spanish manuscripts. In addition, we will strive for a culturally appropriate review process. 


\section{Electronic format}

An electronic format for JSACP allows for greater distribution and access for readers both nationally and internationally. Indeed, anyone in the world with internet access can reach the articles in this issue. We hope this will lead to broader dissemination of this important work as well as equity of access. In addition, ecological issues perpetuated by paper printed journals are avoided with an electronic format.

\section{Beginning}

To conclude this beginning, we share our vision of the future if the Journal for Social Action achieves its goals. We encourage you to connect to this vision, build on it, help us refine it, and move energetically with others toward the world we know is possible.

Scholars, activists, and community members will jointly organize, carry out and reflect on projects of social transformation that restore hope, establish equity, reduce violence, and foster creativity and meaning. Systemic interventions for addressing oppression will be seamlessly integrated with interpersonal counseling and individual change. These experiences will be documented and shared widely in ways that multiply their impact by encouraging further reflection, critique, and collective wisdom. 'Clients' will shape the design and objectives of research on psychosocial interventions. Students in counseling and psychology will devote as much time and energy to understanding the workings of philosophy, religion, culture, economics, and politics as to mastering knowledge of physiology and statistics. Our work will be culturally relevant and training and practice will strive for continuous growth. The fields of counseling and psychology will be recognized as major forces that accompany and energize the progressive movements for social justice, ecological sustainability, and peace. The work of counselors and psychologists will influence public policy to increase access, equity and justice regardless of ability status, economic resources, ethnic background, age, size, language, religion, sexual orientation, sexual identity, gender, nationality, indigenous status. Constructive dialogue practices will be creatively employed to establish collaborative efforts to resolve the very large problems of our day.

\section{References}

Counselors for Social Justice (n.d.). Retrieved on April 15, 2007 from http://counselorsforsocialjustice.com/mission.html)

Freire, P. (1993). Pedagogy of the oppressed. New York: Continuum. 
Journal for Social Action in Counseling and Psychology

Volume 1, Number 1 Spring, 2007

Lewis, J., Arnold, M. S., House, R., \& Toporek, R.L. (2002). ACA Advocacy Competencies. Advocacy Task Force, American Counseling Association. Retrieved January 15,2005 , from http://www.counseling.org/Content/NavigationMenu/RESOURCES/ADVOCACYCOMPETE NCIES/advocacy competencies1.pdf

Martín, Baró, I. (1994). Writings for a liberation psychology. Cambridge, MA: Harvard University Press.

Psychologists for Social Responsibility (n.d.). Retrieved on April 15, 2007 from http://www.psysr.org/about\%20us.htm 